\title{
A valoração da pesca em águas continentais
}

Ian G. Cowx - University of Hull International Fisheries Institute, Hull HU6 7RX, UK E-mail: i.g.cowx@hull.ac.uk

Oriana Almeida - Núcleo de Altos Estudos Amazônicos da Universidade Federal do Pará/NAEA/ UFPA. E-mail: oriana@ufpa.br

C. Bene-CGIAR, The World Fish Centre, 1st Floor, 15 G Radwan Ibn El Tabib Street, Giza, 11511 Eygpt. E-mail: c.bene@cgiar.org

R. Brummett-The WorldFish Centre, BP 2008, Yaoundé, Cameroon R. E-mail: brummett@cgiar.org

S. Bush - Australian Mekong Resource Centre (AMRC), Division of Geography, School of Geosciences, University of Sydney, NSW, Australia. E-mail:simon.bush@wur.nl

W. Darwall - IUCN - The World Conservation Union, 219c Huntingdon Road, Cambridge, CB3 ODL, UK. E-mail: will.darwall@ssc-uk.org

J. Pittock - World Wildlife Fund, 1250 24th St. NW, Washington, DC, USA. E-mail: jpittock@wwf.org.au

M. van Brakel - Institute of Aquaculture, University of Stirling, Scotland, UK. E-mail:mlv1@stir.ac.uk

\section{Resumo}

A pesca tem sido, e provavelmente continuará sendo, uma importante fonte de alimento e renda para sociedade. Nesse trabalho os autores mostram que o valor econômico total da pesca nem sempre é reconhecido. O valor econômico total (VET) em rios pode ser dividido em valor de uso direto e valor de não uso/valor de preservação. VET é a soma de todos os valores de uso e não uso, não importando como são derivados. Os autores mostram que há extrema dificuldade de valorar o valor econômico total o que resultado na baixa valoração da pesca para o setor como um todo. A falta de progresso neste campo é resultado do fraco diálogo entre cientistas e os gestores com os especialistas em economia ambiental e ecológica. A importância integral da pesca pode seer abordada a partir do ponto de vista das populações tradicionais e seu modo de vida que depende de vários recursos naturais. A integração de estudos sobre a pesca precisam ser promovida para incentivar o uso sustentável dos recursos aquáticos em geral eda pesca fluvial, em particular e para trazer àl luz a real importância do setorpesqueiro paraa sociedade.

\begin{abstract}
Fishing has been, and will probably continue to be, an important source of food and income for society. The authors of this study show that the total economic value of fishing has not always been recognized. The total economic value (TEV) in rivers may be divided into direct use value and non-use value/preservation value. TEV is the sum of all value of use and non-use, regardless of their origins. The authors show that there is a great difficult in setting the total economic value, due to low valorization of fishing for the sector as a whole. The lack of progress in this field results from a weak dialogue between scientists, the authorities and experts in environmental and ecologic economics. The full importance of fishing may be approached from the populations' point of view and their livelihood which depends on various natural resources. The integration of studies on fishing needs to be promoted to encourage the sustainable use of all aquatic resources, more specifically, to bring into the open the real importance of the fishing sector to society.
\end{abstract}

\section{Palavras-chave}

Pesca. Valor de Uso. Valoração.

\section{Keywords}

Fishing. Value in use. Valorization 


\section{INTRODUÇÃO}

A pesca tem sido, e provavelmente continuará sendo, uma importante fonte de alimento e renda para sociedade (COWX, 2002c). No entanto, sua importância relativa em relação aos outros sistemas de produção de alimentos tem evoluído, especialmente na última metade do século, devido a maneira que a pesca vem sendo explorada (FAO, 1997). Isso é especialmente verdade nas atividades pesqueiras das águas continentais com diferentes cenários a serem promulgados nos países densamente povoados e altamente industrializados das regiões norte temperadas e dos países desenvolvimento das regiões tropicais (ARLINGHAUS; MEHNER; COWX, 2002). Essas diferenças são em grande parte um resultado dos contrastes dos objetivos sociais e econômicos para a pesca em águas continentais e as diferentes maneiras que elas são manejadas (Tabela 1, segundo WELCOMME, 2001). O manejo da pesca nos países industrializados foca quase que exclusivamente em recreação e conservação, enquanto que o objetivo nos países em desenvolvimento continua a ser em segurança alimentar, embora começa a sergir uma mudança dando ênfase à pesca recreacional (COWX, 2002c) e à conservação (COLLARES-PEREIRA; COWX; COELHO, 2002) como resultado da globalização e da influência dos protocolos internacionais como a Convenção da Biodiversidade.

Tabela 1. Diferentes estratégias para a gestão das águas interiores para a pesca nos países desenvolvidos e países em desenvolvimento (baseado em WELCOMME, 2000, 2001, levemente modificado).

\begin{tabular}{lc}
\hline Industrial (temperado) & Economia Emergentes (tropical) \\
\hline Conservação/Preservação & Objetivos \\
Esportiva & Fornecimento de alimentos \\
\hline & Renda \\
\hline Pesca Esportiva & Mecanismo \\
Recuperação de hábitat & (Comercial) Pesca para alimentação \\
Estocagem respeitando o meio ambiente & Modificação do habitat \\
& Enriquecimento, através de estocagem \\
Aquicultura intensiva & intensiva \\
\hline & Aquicultura extensiva, integrada, e rural \\
\hline Capital intensivo & Econômico \\
\hline
\end{tabular}

Essa diversificação de objetivos que surge por causa da crescente exploração dos recursos da pesca continental, em temos de esforço e de eficiência de pesca, tende a reduzir oportunidades para a produção de peixe como alimento e muda o uso de recursos para os usos recreativos (SMITH., 1986; RANDONSKI, 1995). Consequentemente, na maioria dos países temperados a pesca esportiva ou de lazer são os componentes dominantes do sistema de pesca continentais que evoluíram a partir um simples foco de produção de alimentos (FAO, 1999; WELCOMME, 2001; COWX, 2002c). Nos países em desenvolvimento segurança alimentar e emprego continuam como foco primário (FAO, 1997), apesar das grandes mudanças nos usos dos recursos aquáticos desses países.

Além disso, padrões de uso múltiplos em países industrializados tem criado um clima muito distinto para o desenvolvimento da pesca continental (FAO, 1997). Atividades como agricultura, represamento, controle de inundação, desflorestamento, navegação, recuperação de áreas úmidas, urbanização, hidroelétricas, captação e transferência de água e eliminação de resíduos (COWX, 2002a) têm alterado profundamente o ecossistema de água doce, provavelmente mais que o ecossistema terrestre (VITOUSEK et al., 1997; COWX, 2000). Como resultado, a maioria dos ecossistemas de águas doce nos países industrializados está consideravelmente impactadas (DYNESIUS; NILSSON, 1994; VITOUSEK et al., 1997). Diversificação similar do uso dos recursos aquáticos prevalece em países em desenvolvimento (NGUYEN KHOA; LORENZEN; GARAWAY, 2003; NGUYEN KHOA et al., 2003), mas o impacto é menos dramático e a pesca para alimentação continua uma atividade sustentável, apesar da pesca também estar sob a ameaça do desenvolvimento e mudanças nas atividades de manejo para apoiar o cultivo de peixe (ARAUJO-LIMA et al., 2003; PUSEY, 2003) e a aquicultura (VAN BRAKEL; MUIR; ROSS, 2003). Nesse contexto, a captura e cultivo de peixes devem ser vistos como complementares e não como alternativas (VAN BRAKEL et al., 2003), dado que isso poderia potencialmente levar para a redução produtiva de um corpo de água particular. A aquicultura convencional não é necessariamente uma opção para o pobre rural e o redirecionamento de recursos da captura pesqueira poderia contribuir para insegurança alimentar. Nessas circunstâncias, a aquicultura deve está focada no enriquecimento da produção natural de recursos acessíveis ao pobre rural.

Basicamente, a pesca em águas continentais pode ser encarada como organismos em evolução (Figura 1), com as principais etapas no ciclo de vida de 
uma pesca continental que inclui uma primeira fase voltada para a produção de alimentos, seguido de um interesse crescente na pesca esportiva, e surgindo ao final interesses estéticos e de conservação da natureza (SMITH, 1986). Embora esse processo seja contínuo, países industrializados podem ser vistos em uma extremidade do espectro e países em desenvolvimento no outro extremo, dependendo da escala de industrialização que teve lugar. Isso é, de qualquer forma, uma simplificação porque a necessidade que segurança alimentar tem desencadeado atividades, tais como aquicultura e estratégias de enriquecimento de estoque de peixes (baseado no cultivo de peixes), os quais reabastecem ou ajudam a produção pesqueira, especialmente nos países em desenvolvimento (veja PERT, 1998, para uma revisão sobre o tema). Deste modo, na maioria das regiões do mundo os principais impactos sobre pesca em águas interiores não são originários da pesca em si, mas fora da pesca (e.g. FAO, 1997; GARCIA, et al., 1999; WELCOMME, 2001). A necessidade de um esforço concentrado para prevenir e reduzir a degradação, bem como manter a conservação dos peixes de água doce e pesca como um recurso comum renovável, ou entidades em seu próprio direito, são os maiores desafios do desenvolvimento sustentável das águas continentais (FAO, 1999).

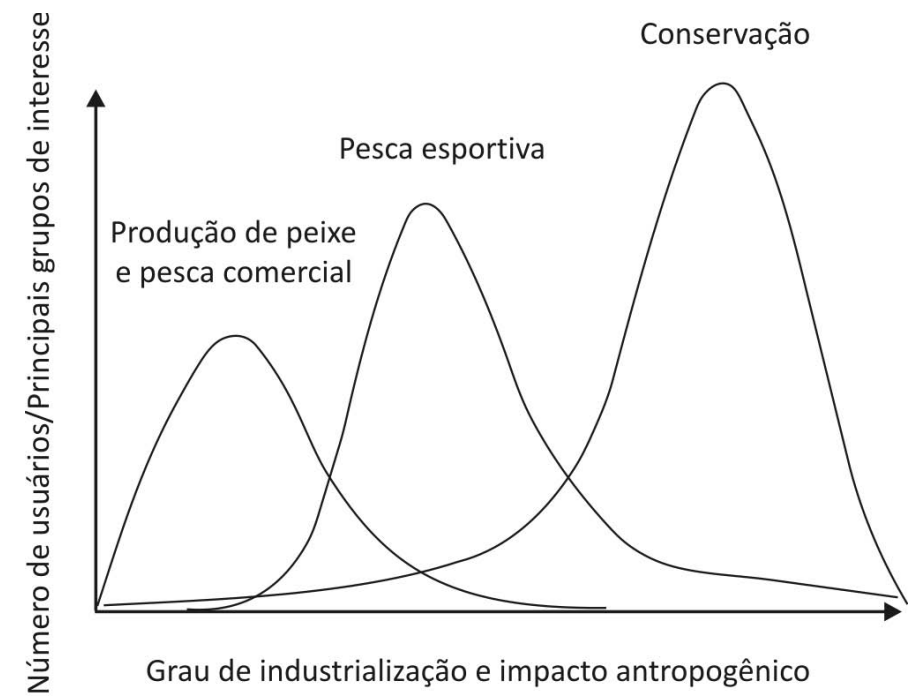

Figura 1. Evolução geral da pesca ao longo de um gradiente de industrialização (modificado de SMITH, 1986).
Um dos aspectos subjacentes relativos a essas mudanças que tem recebido pouca atenção é o valor da pesca e dos recursos aquáticos, incluindo a importância dos serviços dos ecossistemas e da biodiversidade. A pesca é subvalorizada em múltiplos cenários aquáticos de usuários de recursos naturais e isso tem contribuído para as mudanças descritas (COWX, 2002c). No entanto, há que reconhecer que em algumas comunidades rurais, a pesca é considerada de pouca importância e, portanto, de valor mínimo e é importante entender porque a pesca é valorada de formas diferente entre estas localidades (BENE; NEILAND, 2003). Esse artigo examina a importância da valoração precisa da pesca de grandes rios (e em todos os ecossistemas) e como tal informação pode ser usada para manter, melhorar e desenvolver a pesca de águas continentais e serviços de ecossistemas, tanto da perspectiva da exploração como da conservação, para as futuras gerações.

\section{TENDÊNCIAS DA PESCA CONTINENTAL}

Embora a contribuição líquida da pesca em águas interiores para a produção total do pescado mundial seja pequena em comparação com a captura da pesca marinha e da aquicultura (Figura 2a), esta tem mantido uma tendência de crescimento de cerca de dois por cento ao ano, no nível mundial (FAO, 2002). Entretanto, este crescimento não corresponde à verdadeira imagem elucidada a partir de uma análise regional (Figura 2b). Declínios líquidos nas capturas são predominantes na Europa, muitos dos quais ocorreram após a descentralização das economias do Leste Europeu e América do Norte. Os principais aumentos foram na Ásia e África, sendo esta última principalmente devido ao maior rendimento de lagos, especialmente pela introdução da Perca-do-Nilo, Lates niloticus (L.), do lago Vitória. Os números de produção na Ásia aumentaram em relação a uma série de fatores, nomeadamente a proliferação do cultivo de peixe, na China e Bangladesh, e também por causa da coleta mais confiável de dados e estatísticas, por exemplo, os países de Mekong mostram a verdadeira extensão da exploração. Apesar dessas tendências, a pesca natural dos rios se mostram desfavoráveis de maneira geral. Em todo o mundo, não há dúvida de a pesca no rio traz valiosas contribuições para as atividades de lazer e para a segurança alimentar, mas seu desempenho é, em geral, sobre a decadência ou a mudança de características. 


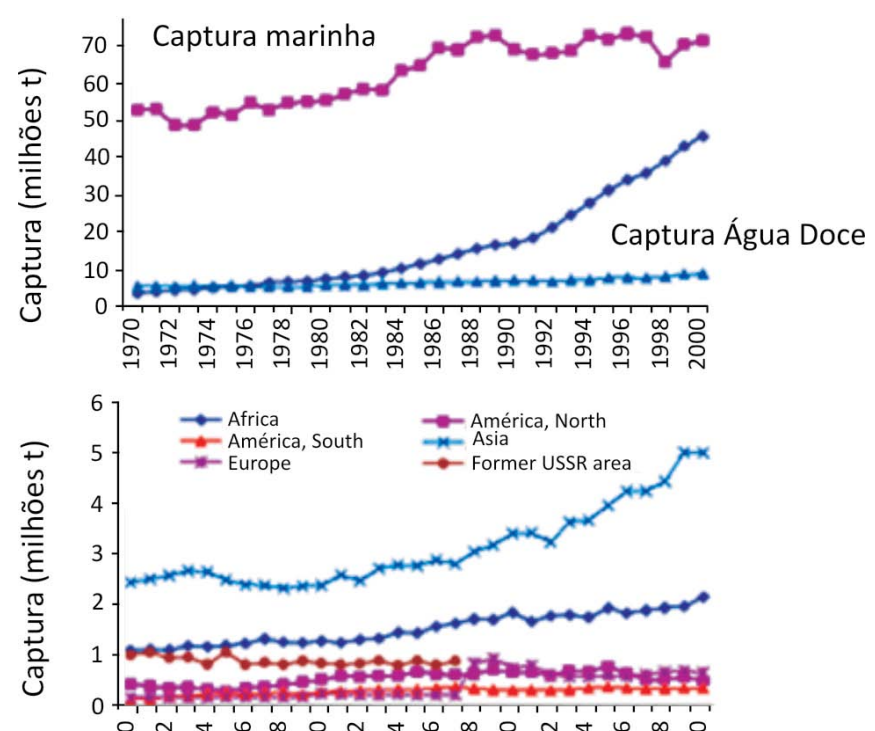

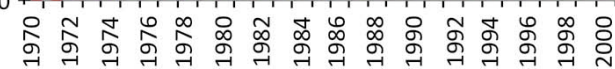

Figura 2. a) Tendências da produção de aquicultura e da pesca marinha e em águas continentais, entre 1970 e 2000 e, b) capturas de água doce por região continental (dados europeus até 1988, após inclui dados da ex-URSS) (Fonte: FAO, 2002). Note que a subnotificação de captura por parte de países e dados incompletos sobre pesca esportiva sugerem que as capturas em águas continentais podem ser pelo menos duas vezes tão elevada como mostrado na figura (FAO, 1999).

Em toda a literatura e bases de dados estatísticos em formato eletrônico, a captura da pesca comercial/artesanal/subsistência dos principais rios geralmente indicam tendências de declínio, o que tem implicações diretas para o modo de vida rural (BENE; NEILAND, 2003; HAND, 2003). Em contrapartida, melhorias na captura da pesca recreativa/esportiva são evidentes na Europa Ocidental e na América do Norte como um resultado da recuperação e atividades de repovoamento, como por exemplo, no Rio Reno (BRENNER, et al., 2003). No entanto, em ambos cenários, a estrutura da pesca e das comunidades de peixes estão mudando. $\mathrm{O}$ aumento da pressão sobre a pesca geralmente resulta em uma queda de rendimento, assim como no processo de "fish down" da cadeia alimentar que afeta a composição da captura, passando a capturar indivíduos e espécies que amadurecem com um tamanho pequeno e/ou com menor idade. (p.e. OUEME DELTA FISHERIES; WELCOMME, 2001). Esses peixes de pequeno porte de maturação precoce tendem a ser economicamente menos valiosos e menos desejáveis que as espécies predadoras de grande porte, que são removidos na primeira fase da pesca. Não obstante este argumento, estes peixes de pequeno porte são nutritivamente importantes e frequentemente contribuem de forma relevante para a segurança alimentar em áreas rurais. Da mesma forma, o aumento da pesca recreativa por meio de estocagem e introduções, alterou a estrutura das comunidades de peixes aumentando as espécies consideradas desejáveis por pescadores de linha, e em geral em detrimento das espécies naturais (COWX, 2002c). Estas mudanças nas estruturas e funções na pesca não apenas tem um impacto marcante sobre o valor econômico da pesca, mas também tem um considerável custo ambiental (ARLINGHAUS et al., 2002).

\section{POR QUE VALORIZAR BENS AMBIENTAIS?}

Apesar da evolução recente da pesca em águas continentais, ela tem, sem dúvida, uma alta importância socioeconômica e sociocultural e proporcionam "uma miríade de benefícios para a sociedade" (WEITHMAN, 1999; WELCOMME; NAEVE, 2001; PITCHER; HOLLINGWORTH, 2002). Entretanto, os benefícios criados pela pesca em águas continentais são difíceis de agrupar, quantificar e avaliar (ver TALHELM; LIBBY, 1987; KEARNEY, 1999, 2002). Há um grande número de razões para isso, incluindo o fato de ser difícil estimar valores para fatores como o valor da pesca artesanal e de subsistência de redução de risco e vulnerabilidade em relação à pobreza de ou ao alto valor cultural e social, frequentemente em termos de solidariedade comunitária, festivais e conexões espirituais, especialmente em países agrários. Este problema, porém, não deve ser usado como um argumento para não valorizar os benefícios da pesca em águas continentais. Três principais argumentos existem para estimar preços de bens ambientais, como a qualidade do rio e proteção da função e da biodiversidade do ecossistema aquático, incluindo a pesca de rio (com base em NAVRUD, 2001).

Primeiro, existe um ótimo social quantitativo e qualitativo dos bens ambientais onde o custo marginal da oferta do produto é igual ou menor que o benefício marginal, expresso como a demanda pública para o bem. Este argumento decorre da crescente sensibilização entre os formuladores de políticas, de que o objetivo de degradação ambiental diferente de zero deve ser aceita e que tradeoffs podem ser vistos em termos econômicos como custos e benefícios. Embora os custos de fornecer qualidade ambiental (geralmente os custos de proteção e reabilitação) sejam relativamente fáceis de determinar, a demanda por qualidade 
ambiental é mais difícil de se avaliar em termos de benefícios correspondentes. Por exemplo, melhorando a qualidade da descarga dos efluentes em rios irá reduzir poluição e aumentar a diversidade e potencial para exploração dos estoques pesqueiros. $\mathrm{O}$ mesmo resultado pode ser atingido através do enriquecimento de alevinos. Enquanto os custos sociais de programas de controle de poluição são relativamente conhecidos, os benefícios sociais em termos de melhorias de estoque pesqueiro não são. Para calcular o nível ótimo de controle de poluição, ou nível ótimo de regime de enriquecimento com alevino existe a necessidade de se conhecer seus benefícios sociais. Para conduzir uma análise completa de custo-benefício da poluição, os benefícios sociais de todas as melhorias ambientais precisam ser calculados. Assim, não apenas o aumento do estoque de peixes, mas também a redução dos custos de tratamento de água para a agricultura e uso humano, redução do impacto na saúde, aumento da utilização para fins recreativos e outros danos para os ecossistemas estuárinos ou marinhos etc., devem ser valorados.

Bens ambientais possuem muitas características de bens públicos, já que indivíduos em geral não podem ser proibidos de desfrutar das melhorias ambientais e nem podem evitar a degradação ambiental. Assim, esses produtos geralmente não são comprados e vendidos em mercados e não têm preços de mercado ou tem preços de mercado que não correspondem aos custos sociais marginais de seu fornecimento. No entanto, existe a necessidade de saber os valores marginais ou preços dos bens ambientais, para poder comparar os custos e benefícios marginais e definir um nível econômico eficiente pelo fornecimento desses bens e os correspondentes objetivos de políticas ambientais. Preços ambientais são também necessários para decidir quais regulamentos e quais projetos são socialmente desejáveis. Valores monetários permitem que alternativas sejam classificadas e, com referência a outros usos dos recursos avaliados, permitem que o custo de oportunidade (o valor de oportunidades perdidas, com objetivo de obter um benefício) de cada opção seja comparado.

Segundo, se os bens ambientais não são avaliados explicitamente, decisões políticas vão valorizá-las implicitamente, o que muitas vezes produzem preços arbitrários e inconsistentes, porque os tomadores de decisões geralmente desconhecem que eles fazem essas avaliações. Para ilustrar este argumento, pode se considerar um projeto de desenvolvimento de energia hidrelétrica. Isso pode representar impactos ambientais na pesca recreativa e/ou na pesca comercial, atividades recreativas ao ar livre, agricultura, exploração florestal, qualidade da água e suprimentos, objetos históricos e culturais, estética da paisagem e do ecossistema em geral, que são geralmente apenas definidos de forma qualitativa. Raramente é feita qualquer tentativa para calcular o valor destes impactos ambientais. Análises de custo-benefício (ACB), tendo em conta todos os benefícios e custos sociais, exceto o valor ambiental, tendem a ser baseados no valor presente líquido. Se o valor presente líquido de uma barragem concebida para ser operada por 50 anos é de US $\$ 10$ milhões, com uma taxa de desconto de 5 por cento ao ano, os benefícios líquidos anuais são cerca de US\$700 000. Se a construção de uma barragem tem consequências apenas para uma comunidade local de 20000 pessoas, os tomadores de decisões avaliaram os danos de forma implícita de que cada pessoa está disposta a pagar menos de 35 dólares cada ano para evitar o dano ambiental. Este valor é muito menor se o rio for de importância nacional ou internacional e se mais pessoas forem afetadas. No entanto, as pessoas não foram questionadas sobre suas preferências e se podem estar dispostas a pagar mais do que este montante para evitar os efeitos negativos no ambiente e preservar os rios (NAVRUD, 1994). Consequentemente, o custo total social de um projeto hidrelétrico muito provavelmente irá exceder os benefícios. Assim, do ponto de vista econômico uma barragem não deve ser construída. Cuidados devem ser tomados quando se adota esses tipos de avaliações, dado que existe uma grande incerteza quando transferindo benefícios ou custos de um estudo de caso para o local onde a análise de dados está sendo feita. No entanto, essa incerteza é considerada aceitável na análise de custo-benefício, dado que outros fatores de benefícios e custos podem facilmente ser equivalentes ou ainda mais incertos (NAVRUD 1994).

Em terceiro lugar, há a necessidade de valorizar a pesca continental e biodiversidade aquática nos levantamentos de impactos ambientais e situações de resolução de conflito. Esta necessidade resulta em grande parte do argumento anterior sobre tomadores de decisão fazendo avaliações implícitas. Quando decisões são feitas em grandes projetos de desenvolvimento, a pesca tem que apresentar fortes argumentos econômicos, caso contrário, ela é substituída e sofre frente aos setores economicamente mais fortes, como hidrelétrica, abastecimento de água e desenvolvimento agrícola (ver, por exemplo, HALLS; SHANKAR; BARR, 2003; KAUNDA; CHAPOTK, 2003). Em muitos aspectos, este argumento é o mais importante devido ao reconhecimento de que pesca continental é apenas um dos elementos de um ambiente de uso múltiplo e o setor frequentemente apresenta um fraco argumento para a sustentabilidade porque é subvalorizado em termos reais. Esta questão será discutida em mais detalhe mais tarde. 
Apesar dos argumentos apresentados acima, há algumas objeções na atribuição de valores aos sistemas naturais. $O$ primeiro refere-se ao papel dos preços de mercado, que implica que os consumidores são os melhores juízes do valor de um sistema e que as considerações da comunidade são irrelevantes. Isso pode ser combatido quando se nota que a proposta da valoração é fornecer mais informações para o processo político de gestão de recursos, em vez de deixar o processo ser totalmente influenciado por considerações políticas. $\mathrm{O}$ segundo problema é o pressuposto de que os consumidores entendem o valor da prestação de serviços ecológicos fornecidos pelos recursos biológicos.

A dificuldade gira em torno da complexidade do processo ecológico e, portanto, da necessidade de tratar o sistema como um todo. Uma implicação é que se houver um caso para a proteção do sistema, um grande cuidado deve ser tomado em um nível mais moderado de uso por causa da freqüente falta de conhecimento sobre quais espécies ou partes do sistema são necessários para manutenção do ecossistema e que parte é redundante. Por exemplo, o processo ecológico associado com a vegetação aquática é necessário para promover condições apropriadas para favorecer o habitat dos peixes. É frequentemente difícil avaliar no entanto, o grau de cobertura vegetal necessário para fornecer essa situação favorável. O terceiro problema é que as técnicas usadas para determinar o valor econômico tendem a ignorar muitas considerações morais e de equidade. $\mathrm{O}$ argumento econômico é que as técnicas são completamente distintas do reconhecimento político de que as desigualdades existem e dos instrumentos necessários de política para reduzir ou removê-las.

\section{VALORES DOS BENEFÍCIOS E IMPACTOS}

Geralmente, três domínios se distinguem onde os benefícios associados à pesca do rio são considerados: benefícios econômicos, sociais e ecológicos (Tabela 2). Além disso, ao analisar os impactos alguns componentes adicionais precisam ser levados em consideração: (a) impacto negativo da pesca nos ecossistema aquáticos; e (b) os impactos, ameaças e restrições sobre a pesca de rio.
Tabela 2. Os benefícios socioeconômicos da pesca em águas continentais e os impactos sobre a pesca em águas continentais (modificado de WEITHMAN, 1999).

\begin{tabular}{lc}
\hline \multicolumn{1}{l}{ Valores } & \multicolumn{1}{c}{ Impenactócio Econômico } \\
\hline $\begin{array}{l}\text { Uso direto: Consumo, não } \\
\text { consumo, indireto }\end{array}$ & Direto, indireto, induzido \\
$\begin{array}{l}\text { Não uso: Opção, existência, } \\
\text { bequest }\end{array}$ & \\
\hline & Benefício Social \\
\hline $\begin{array}{l}\text { Cultural, social, psicológico, } \\
\text { fisiológico }\end{array}$ & Qualidade de vida, bem estar social \\
\hline & Benefício Ecológico \\
\hline - & $\begin{array}{l}\text { Mitigação, reabilitação, manejo, } \\
\text { "benefícios" (impactos) negativos } \\
\text { Outros impactos de degradação } \\
\text { ambiental, baixa prioridade social, } \\
\text { conflitos entre usuários, restrições }\end{array}$ \\
\hline
\end{tabular}

\section{BENEFÍCIOS ECONÔMICOS}

Valor econômico total (VET) da pesca em rios pode ser dividido em dois componentes principais: a) Valor de uso direto; e b) Valor de não uso/valor de preservação. VET é a soma de todos os valores de uso e não uso, não importando como são derivados

O valor de uso direto do estoque pesqueiro pode ser dividido valor de consumo, de não-consumo e valor indireto (RANDALL, 1987; BISHOP; BOYLE; WELSH, 1987, Table 2). Valor de consumo inclui a renda líquida de pesca comercial (ou seja, de venda de pescado menos o custo de fatores de produção), a captura por pescador de linha ou caniço, ou o valor econômico da pesca esportiva. Esse é o principal critério usado para avaliar pesca em países industrializados ou em desenvolvimento. Veja por exemplo Almeida, Lorenzen e McGrath (2004). Uso de não consumo (que os indivíduos derivam que não é para consumo, ou mudança física dos recursos naturais) inclui a pesquisa ou turismo, como por exemplo, 
observar salmão subindo cachoeira acima, ar fresco e outros bens públicos que não destroem os recursos pesqueiros. Utilização indireta (também conhecida como valores da função ecológica) compreende todas as funções ecológicas dentro de um sistema, ou pode incluir atividades em outros locais (ou seja, peixes que não são usados diretamente para o alimento ou esporte), incluindo a comercialização, a leitura sobre a atividade pesqueira ou atividades especiais no local da pesca (RIECHERS; FEDLER, 1996). Uma derivação da valoração de uso direto e indireto são valores de opção (valor de um indivíduo manter a opção de utilizar um recurso em algum momento no futuro). Este pode ser visto como um seguro extra contra o risco de perder bens e serviços que são importantes na vida de uma comunidade. Como tal, eles também fazem parte da preservação valores (ver abaixo).

Valores de não uso são valores que podem ser atribuídos a sistemas como resultado da satisfação proveniente de certas pessoas do simples conhecimento que um certo sistema existe, embora não obtenha qualquer bem ou serviços direto ou indireto disto. Valor de não uso é dividido em valores de "bequest" (valor para um indivíduo que sabe que os recursos estão disponíveis para uso de futuras gerações) e o valor de existência (valor para um indivíduo em saber que existe um recurso e que os outros têm a oportunidade de usá-lo) (RIECHERS; FEDLER, 1996; WEITHMAN, 1999; PEIRSON, et al., 2001). Valores de existência são, talvez, mais difundidos entre os países industrializados (no Reino Unido, por exemplo, a Royal Society for the Protection of Birds sobrevive de doações, gerando alto rendimento com base nesse tipo de fonte de renda e direciona o seu rendimento à proteção de habitat), mas não somente. Existem também valores de preservação, que são similares aos valores de opção. Estes são valores associados àqueles que se beneficiam direta ou indiretamente da preservação e do sistema natural. Esse é um valor para comunidades que têm acordos pesqueiros (vere por exemplo, McGRATH; et al., 1993; McGRATH, SILVA; CROSSA, 1998). Nesta situação, é possível criar um mercado de serviços ambientais, como crédito de carbono, redução da erosão e controle de fogo.

Além disso, um projeto pode ocasionar impactos irreversíveis, como extinção de uma espécie de peixe, um valor de quase-opção pode ser avaliada e usada como um fator de correção para o valor econômico total. Isto é equivalente ao princípio da precaução e relacionado ao aumento do valor da informação sobre o valor da espécie de peixe adquirida pela não implementação de um projeto com impactos irreversíveis. Outro conceito relacionado é o Safe Minimum Standard
(BISHOP et al., 1978), que diz que deve se preservar a menos que os custos sejam intoleráveis. O desafio é definir o quão alto os custos podem ser antes de se tornarem intoleráveis.

Existem duas abordagens principais para a valorização de bens sem mercado: i) métodos baseados nas preferências individuais; e ii) métodos baseados nas preferências dos peritos e tomadores de decisão. Esse último inclui métodos como análise de decisão multi-critérios, técnicas Delphi e avaliação implícita eliciadas de decisões políticas (veja acima). Esses métodos podem ser vistos como uma ferramenta complementar para a análise de custo-benefício (ACB) e não será discutida posteriormente. Técnicas de valoração baseadas nas preferências individuais podem pode ser divididas em duas abordagens: a preferência revelada e métodos de preferência declarada (Tabela 3).

Tabela 3. Classificação de técnicas de avaliação ambiental com base nas preferências individuais (modificado de NAVRUD, 2001).

\begin{tabular}{l|l|l}
\hline & Indireto & Direto \\
\hline Preferência revelada & Produção familiar & Mercados simulados \\
$(\mathrm{PR})$ & Abordagens de Função (HPF) & \\
& - Método do custo de viagem & \\
& - Custos evitados (CE) & Preços de mercado \\
& Método do preço hedônico & Custo de reposição (CR) \\
\hline Preferência declarada & $\begin{array}{l}\text { Classificação contingente (CR) } \\
\text { (PR) }\end{array}$ & Valoração contingente \\
& Escolhas de Experimentos (EE) & (VC) \\
\hline
\end{tabular}

Métodos de preferência revelada usam dados de comportamento observado de entrevistados em mercados relacionados com valores de não uso. O método custo de viagem assume que os custos de viagem para o local de lazer (incluindo despesas de viagem direta, hospedagem e despesas com alimentos, etc.) são um bem complementar para atividades recreativas. A premissa básica do método é que a quantidade de viagens a um local de recreação irá diminuir com o aumento da distância percorrida (e os custos de viagem), mantendo as outras coisas iguais, proporcionando assim uma medida indireta da disposição a pagar (ou seja, o excedente do consumidor). No método de preços hedônicos o bem ambiental é considerado como uma das várias características que afeta o preço da propriedade, por exemplo, ruído, qualidade do ar e da água e paisagens estéticas (incluindo vista para o rio) e é de pouca relevância para a valoração de estoque de pesca continental. 
Métodos de Preferência Declarada valoram o bem ambiental em questão através da construção de um mercado hipotético para o bem - e essa é a grande crítica à abordagem. Entretanto, os métodos de preferência declarados são úteis porque fornecem mecanismos para estimar valor de uso e não uso de um valor futuro de um bem ambiental.

Método de preferência declarada pode ser dividido em abordagens diretas e indiretas. A Valoração Contingente (VC) é o método mais comumente utilizado, mas principalmente para a pesca recreativa. Dentre os artigos apresentados à conferência de grandes rios II (LARS2), apenas Alam (2003) tentou avaliar pesca comercial baseado nessa abordagem, durante um estudo em Bangladesh. Ao longo dos últimos anos, abordagens indiretas de classificação contingente (CC) e de Escolhas de Experimentos (EE) também ganharam popularidade. A principal diferença entre estas duas abordagens é que enquanto o método CC é tipicamente de duas opções (referendo), CE emprega uma série de questões com mais de duas opções, que são concebidos para obter respostas que permitam estimar preferências sobre os atributos da qualidade do ambiente.

Um levantamento da Valoração Contingente (VC) constrói cenários que oferecem diferentes ações possíveis do governo no futuro. Sob o mais simples e comumente formato de pergunta usado na VC (escolha discreta binária ou método de perguntas fechadas), o entrevistado recebe uma oferta de opções entre uma ação que mantém a política do status quo e de uma com o custo maior (por exemplo, aumento de impostos, os preços elevados associados com a regulamentação, ou taxas ao usuário). Basicamente, o entrevistado fornece uma resposta a favor/contra em relação a uma política alternativa (versus o status quo). Fatores como o que uma política alternativa que vai proporcionar, como vai ser fornecido e quanto vai custar e como ela será cobrada (o veículo de pagamento, por exemplo) são especificados.

Um método alternativo de eliciação é aplicado através de lance livre ou formas abertas em que os inquiridos são questionados diretamente sobre: (a) o quanto eles estão dispostos a pagar (DAP) por um serviço ou o aumento que eles estão disponíveis a pagar para manter o acesso a esse serviço, ou (b) o quanto eles estão dispostos a aceitar (DAA) como compensação pela perda do serviço ou caso a mudança não ocorra. Dado que muitas vezes é a melhoria da quantidade e da qualidade das populações de peixe que estão sendo avaliadas, a medida mais adequada é ou excesso de compensação (DAP para a melhoria) ou excedente equivalente (DAA para a mudança que não ocorre). A escolha da DAP ou DAA depende de suposições sobre os direitos e se a mudança é uma melhoria ou deterioração da qualidade ambiental. Geralmente, DAA só é utilizada quando há direitos de propriedade claros para o status quo e as mudanças representam uma deterioração (PEIRSON et al., 2001). DAP, que inclui as despesas atuais e o valor excedente (benefícios que excedem o custo monetário, o valor econômico líquido ou o excedente do consumidor) para os usuários, é uma medida adequada do valor econômico da pescaria esportiva (ver POLLOCK; JONES; BROWN, 1994; RIECHERS; FEDLER, 1996; WEITHMAN, 1999; NAVRUD, 2001, para revisões) e para a pesca de tempo parcial ou a pesca artesanal, comercial ou de subsistência, que são comparáveis as atividades de "lazer". Além disso, o valor que os não usuários colocam sobre a pesca deve ser considerado se o valor econômico total da pesca for ser avaliado.

Apesar das vantagens da utilização de métodos VC de valorar os recursos que não têm o valor de mercado direto disponível, como a manutenção de um habitat intocado ou conservação das espécies sem valor econômico, importantes para influenciar os políticos e tomadores de decisão, os métodos são igualmente abertos à crítica. Por exemplo, indivíduos com tendências pró-ambientais estarão dispostos a pagar mais do que o público em geral, aumentando a estimativa DAP (por exemplo, KOTCHEN; REILING, 2000).

Da mesma forma, quando esforço financeiro se torna uma realidade, os indivíduos tendem a estar menos dispostos a pagar do que quando é apenas uma consulta. Esses métodos são também difíceis de usar nos países em desenvolvimento onde a população rural não tem percepção do valor econômico de bens e serviços ambientais.

Estas estimativas da DAP ou do excedente do consumidor podem, no entanto, ser utilizadas na análise de custo-benefício para avaliar os benefícios das melhorias da qualidade ambiental em relação às perdas econômicas (custos) para outros usos da água, tais como irrigação ou geração de energia hidrelétrica. Willis e Garrod (1999), por exemplo, investigaram os benefícios para os pescadores e usuários de outras atividades recreativas (como por exemplo, natação, observação da vida selvagem), através do aumento dos fluxos em rios de baixa vazão na Inglaterra e demonstraram que os benefícios para os pescadores superam os custos dos programas para aliviar a baixa vazão dois de sete rios avaliados. $\mathrm{O}$ valor para outras formas de atividades recreativas e valores de não uso justificaram a redução do aliviação de baixa vazão em outros três rios. Somente onde os custos de alívio de baixa vazão foram extremamente altos os benefícios da recreação não excedeu os custos de implementar um regime de fluxo ambiental aceitável nos rios 
pesquisados. Outros estudos também demonstraram que o aumento marginal do baixo fluxo de água pode gerar benefícios para a pesca recreativa, que excedem o valor marginal da água utilizada na agricultura (HANSEN; HALLAM, 1991). No entanto, pode haver também uma perda líquida associada a uma mudança nos regimes de manejo, que beneficiam atividades recreativas, incluindo a pesca, mas que restringem empreendimentos comerciais, tais como geração de energia hidrelétrica.

Lucros através do fornecimento de proteína animal para a sociedade é uma medida útil do valor econômico da pesca comercial porque, da mesma forma que o excedente do consumidor, o lucro é o valor que excede os custos (EDWARDS, 1991). No entanto, os pescadores comerciais experimentam certos valores que não são englobados pelo lucro (LACKEY, 1979; HART; PITCHER, 1998), por exemplo, o excedente do produtor (EDWARDS, 1991). A despeito disso, sem um lucro um empreendimento comercial deixaria a pesca, a não ser que fosse subsidiada. Devido à existência de preços de mercado no setor da pesca comercial, a demanda e as funções de abastecimento permitem a determinação do valor econômico da pesca comercial. Cuidados devem ser tomados quando se comparam as receitas ou os lucros da pesca comercial com valor econômico da pesca recreativa para alocar recursos da pesca, pois estes "argumentos de caráter econômico" derivam fundamentalmente de diferentes conceitos econômicos (ver EDWARDS, 1991 para a crítica). Em vez disso, o valor econômico líquido ou o excedente do consumidor da pesca recreativa e valor econômico líquido da pesca comercial, que são o excedente do consumidor e excedente do produtor, devem ser comparados e sua atribuição deve basear-se na base de trocas incremental em valor econômico líquido (ver EDWARDS, 1991 para mais detalhes).

Gastos de pescadores esportivos ou de pescadores comerciais representam receitas e empregos na economia local. Existem três tipos de impactos econômicos: (1) impactos diretos, que são as compras feitas pelos pescadores, incluindo viagem, alojamento e custos de alimentos, (2) os impactos indiretos, que são as compras feitas pelas empresas para produzir bens ou serviços exigidos por pescadores, e (3) os impactos induzidos, que são as compras de bens e serviços pelas famílias que recebem os salários das empresas produtoras de bens diretos ou indiretos. A soma destes três níveis de impacto é o impacto econômico total (TEI). TEI dividido pelo valor do impacto direto é chamado de multiplicador e reflete o número de vezes que a despesa inicial circula na economia local. Isto pode adicionar um valor considerável para as atividades de pesca. Por exemplo, uma análise do impacto sobre as despesas de pesca (US\$25,6 milhões em 1990) sobre a economia regional nas margens do
Lago Texoma (E.U.A.) encontraram impactos diretos, indiretos e induzidos de despesa equivalente a US $\$ 57,4$ milhões dólares nas vendas totais, US\$23,3 milhões em valor adicionado e 718 postos de trabalho (SCHORR et al., 1995).

\section{BENEFÍCIOS SOCIAIS}

Quatro categorias de valor social se relacionam com a pesca do rio: culturais, sociais, psicológicos e fisiológicos (Tabela 2). Os dois primeiros dizem respeito mais às nações e comunidades regionais, enquanto as duas últimas dizem respeito aos indivíduos (WEITHMAN, 1999).

Os valores culturais representam um sentimento coletivo em relação ao peixe e à pesca. A pesca em rios é um trunfo importante da sociedade e é valorizada pela comunidade como um todo. Valores da sociedade são baseados em relacionamentos entre as pessoas como parte de uma família ou comunidade (por exemplo, a pesca em família). Valores psicológicos são aqueles que dizem respeito à satisfação, motivação e atitudes relacionados com a utilização ou o conhecimento da existência de um tipo de pesca. Valores fisiológicos relacionados com melhorias na saúde humana (por exemplo, redução do estresse) relacionados com a pesca (WEITHMAN, 1999). Os dados sobre a incidência de doenças humanas podem ser obtidos no posto de saúde local ou hospital.

Os impactos sociais são muito evasivo (VANDERPOOL, 1987). Eles estão relacionados à qualidade de vida e ao bem-estar social causado pela pesca (GREGORY, 1987), incluindo as melhorias nos meios de subsistência rural (BENE; NEILAND, 2003; HAND, 2003). Por exemplo, muita atração por parte de pescadores esportivos a um rio poderia gerar renda para a comunidade de pesca comercial e aumentar o bem-estar social, que pode ser medido através de uma melhor qualidade de vida.

\section{BENEFÍCIOS ECOLÓGICOS}

Os benefícios ecológicos da pesca em rio são, normalmente, difíceis de quantificar (KEARNEY, 1999, 2002, Tabela 2). Porque a maioria dos rios está comprometida de alguma forma, há uma tendência crescente de intervenções, quer para melhorar o funcionamento dos sistemas degradados ou para restaurá- 
los (COWX, 1994; COWX; WELCOMME, 1998). Assim, a gestão da pesca nos rios visa principalmente atenuar ou reabilitar as mudanças adversas induzidas pelo homem através da manipulação dos ecossistemas, na tentativa de obter benefícios positivos (BROWN, 2003). Kearney (1999) sugeriu que a comunidade pesqueira consciente em relação à conservação representa uma das maiores forças potenciais para a conservação da biodiversidade aquática. Kearney (2002) insistiu que os usuários da pesca têm um potencial diferenciado em relação aos impactos ecológicos positivos, como a educação, a promoção da responsabilidade ambiental, a ajuda no monitoramento ambiental, gerando apoio e ajuda para a vigilância contra o vandalismo ambiental. Indiretamente, os grupos de interesse da pesca, em alguns países temperados do Norte, especialmente as sociedades de pesca recreativa, pressionaram os governos para reformularem a legislação ambiental e foram as forças motrizes da melhoria da qualidade do rio.

No entanto, nem todas as medidas adotadas na pesca continental tradicional são consideradas positivas. Por exemplo, as medidas de gestão comum, tais como enriquecimento com alevinos e introduções (ARAUJO-LIMA et al., 2003), são sérias ameaças à biodiversidade de peixes (COWX, 2002a; FREYHOF, 2002). Independentemente destes impactos potenciais negativos, uma proporção relativamente alta da sociedade se mantém em contato com a natureza através de ligações com a pesca em águas continentais e, consequentemente, tende a ser mais sensível às questões ambientais do que a maioria da população urbana crescente (LYONS; HICKLEY; GLEDHILL, 2002). Esta tomada de consciência das questões ambientais e a diversidade de ecossistemas pelos protagonistas da pesca (por exemplo, KEARNEY, 1999; CONNELLY; BROWN; KNUTH 2000) é fundamental para o manejo com base no ecossistema (por exemplo, OLSSON; FOLKE; 2001) e sustentabilidade, assumindo que a responsabilidade ecológica seja alcançada. Além disso, o conhecimento indígena, das comunidades pesqueiras e instituições informais (locais) podem desempenhar um papel importante na gestão sustentável dos recursos da pesca (por exemplo, MACKINSON; NOTTESTAD 1998; BERKES; COLDING; FOLKE, 2000; JOHANNES, FREEMAN; HAMILTON, 2000).

\section{UMAOBSERVAÇÃO SOBREAVALORIZACÃO DA BIODIVERSIDADE}

Continua a ser uma exceção colocar valores na diversidade no planejamento de manejo de recursos aquáticos. Uma parte disso pode ser devido a dificuldades na compreensão do conceito de diversidade, enquanto um outro fator pode ser a considerável dificuldades na coleta e análise da informação requerida. Diversidade, no entanto, sustentam a nossa existência neste planeta, e não devem ser ignoradas. Quando não é, decisões que, de outro modo seriam feitas exclusivamente por motivos políticos, devem ser refinadas por uma análise econômica e ecológica do problema.

A biodiversidade é um conceito que descreve a maneira pela qual os diferentes produtos (ou componentes) e serviços (ou funções) de um ecossistema estão organizados. Ele tem três partes - a diversidade genética, diversidade de espécies e a diversidade do ecossistema. Essencialmente, para todas as três partes, o grau de diversidade dos recursos naturais - as medidas da riqueza e a distribuição dentro do sistema, não devem ser confundidas com os próprios recursos biológicos. Por exemplo, a diversidade genética descreve a variação dentro de um conjunto particular - o número de gens e sua distribuição, não do agrupamento ou as características dos gens individuais. Da mesma forma, a diversidade de espécies é uma medida da riqueza de espécies e sua distribuição, mas não é uma descrição de organismos individuais. A diversidade de ecossistemas indica o número e variedade dos tipos de ecossistemas existentes em uma determinada área, mas não descrevem os próprios ecossistemas. Assim, a valorização da diversidade biológica não pode ser equiparada com a valorização dos recursos, embora os dois conjuntos de valores estejam intimamente relacionados.

Da mesma forma que os recursos biológicos, a diversidade biológica é reconhecida por ter valores de uso direto e indireto. A essência da diferença na mensuração do valor dos recursos e o valor da diversidade é que, enquanto a análise anterior está preocupada com a identificação dos valores de uso brutos, na medição dos valores da diversidade, a atenção é dirigida para as medições das mudanças marginais na produção que resultam de mudanças marginais nos insumos relevantes. Medir a variação da atividade econômica que resulta de uma diminuição especifica na diversidade é uma forma de estimar os valores de uso direto e indireto da diversidade. Por exemplo, na medida dos valores de uso direto e indireto da diversidade de espécies de um recife de coral, mudanças tanto na diversidade das espécies de corais como a quantidade total de cobertura com corais afetam a biomassa de peixes. As elasticidades resultantes poderiam ser usadas para o cálculo do valor da diversidade de corais através da estimativa da variação da receita obtida na pesca no recife. Um exemplo de um valor de uso direto da diversidade de ecossistemas é a receita derivada do turismo a partir da observação dos recifes de coral. 
No caso de valor de uso direto, substitutos ecológicos são geralmente mais elusivos que os econômicos. Por exemplo, se a madeira para defumar peixe não puder ser obtida devido a sobre-exploração, mas um substituo que esteja facilmente disponível, for quase tão satisfatório em termos de calor, qualidade da fumaça e facilidade de coleta, o custo econômico de trocar para uma outra alternativa será pequeno. Assim, neste caso, o valor direto da diversidade das espécies será pequeno, apesar do custo ecológico ser alto. Em contraste, se a madeira favorita só puder ser substituída por madeira que tem que ser buscada à grande distância, o custo econômico será então alto, fazendo com que o valor direto da diversidade das espécies também alto.

Valores de uso indireto da biodiversidade podem também ter substitutos econômicos ou ecológicos. Mais uma vez, os benefícios obtidos a partir da degradação de uma gama de serviços ambientais devem ser pesados contra a disponibilidade e utilidade dos substitutos, por exemplo, os valores das zonas úmidas marginais podem ser elevados devido à disponibilidade relativamente baixa de substitutos ecológicos e os elevados custos de substitutos econômicos (por exemplo, plantas de purificação de água, transporte de água, a relocação de comunidades pesqueiras dependentes de zonas úmidas).

No cálculo dos valores de uso direto e indireto da diversidade, há espaço para uma contagem dupla de valores de uso dos recursos e valores de diversidade e tradeoffs. Cuidados devem ser tomados para assegurar que os valores de diversidade sejam usados separadamente dos valores dos recursos para avaliar os impactos sobre a biodiversidade ou ameaças atuais.

\section{PAPEL DE VALORAÇÃO NO MANEJO DE PESCA DOS RIOS}

O valor da manutenção e suporte da função do ecossistema do rio é ilustrado na Figura 3. Um ecossistema saudável gera riqueza para as economias locais e regionais, que apoia implicitamente o modo de vida rural. Neste ciclo, a pesca desempenha três papéis importantes: como um bem público para que todos possam usar e aproveitar; gerando receita para as economias locais; como um catalisador para a regeneração do ecossistema e envolvimento da comunidade. Estes três elementos devem ser interdependentes para se ter sucesso. Sem a paisagem, a biodiversidade e a valor dos recursos aquáticos as pessoas não são levadas a utilizar os rios. Estas qualidades dependem de uma boa gestão e controle ambiental do ecossistema do rio inteiro, incluindo a área de captação do rio e da sua biodiversidade. Se o rio não atrair a participação no uso de recursos, não há nenhum catalisador para o desenvolvimento econômico ou estímulo para o envolvimento da comunidade e não há razão para manter ou melhorar o ambiente de rio.

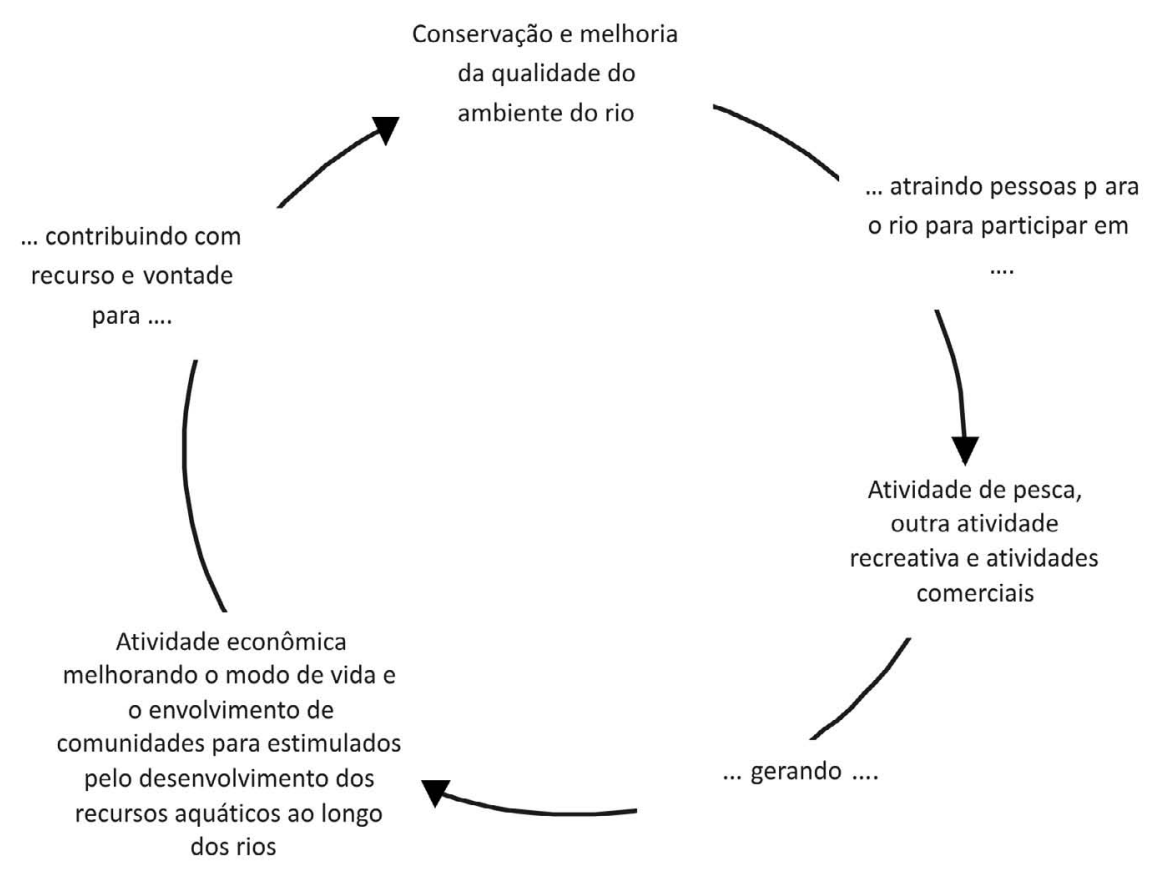

Figura 3. O ciclo do rio que ilustra a importância da participação na manutenção da função dos ecossistemas e no apoio do modo de vida rural.

O princípio subjacente a estes argumentos é o de reconhecer o valor da pesca do rio e do ecossistema para sustentar o modo de vida rural. Isto é destacado no quadro de modo de vida sustentável da DFID (Figura 4) que mostra como os valores de vários ativos são o ponto focal para influenciar a política de melhorar o bem-estar das comunidades ribeirinhas. A abordagem do modo de vida trata questões relacionadas à vulnerabilidade e à redução do risco associado com padrões de exploração dos recursos. Estes são valores que são difíceis de avaliar, mas baixo risco e vulnerabilidade reduzida em relação à pobreza são características muito importantes nas estratégias do modo de vida sustentável e na manutenção da segurança alimentar. 


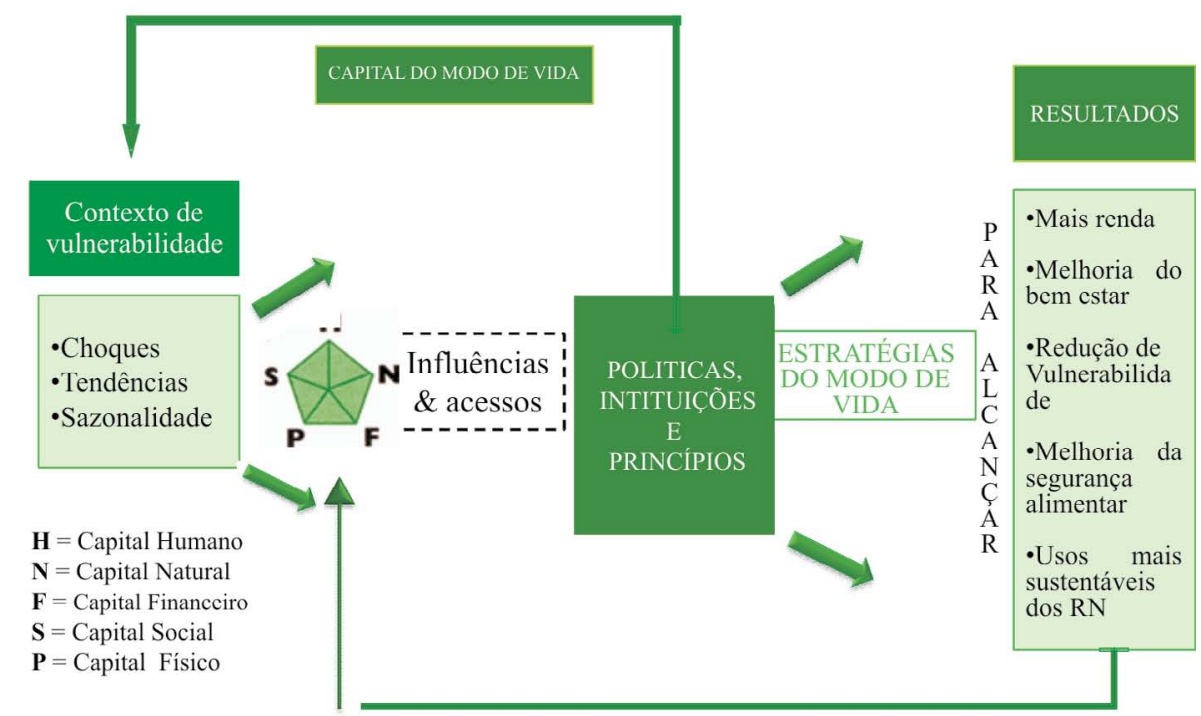

Figura 4. Estrutura do modo de vida sustentável do DFID.

Infelizmente, a pesca de rio está ameaçada por uma grande variedade de fatores e, portanto, as comunidades são muito vulneráveis à mudança, mas a perturbação antropogênica parece estar subjacente ao declínio e à extinção de muitas espécies de peixes (ver COWX, 2002b para revisão). As perturbações principais podem ser divididas em cinco problemas-chave: a introdução de espécies e translocações, o represamento de rios (barragens e açudes, captações de água e sistemas de transferência de água), a deterioração da qualidade da água (poluição, a acidificação eutrophication), a degradação e fragmentação do habitat (canalização e mudança no uso da terra, extração mineral) e a sobre-exploração. Estes problemas parecem ser universais. Embora muitas das questões sejam tratadas nos países desenvolvidos através de legislação ambiental, a taxa de progresso na reversão dos impactos é pateticamente lenta. Além disso, o custo da execução dos programas de reabilitação ou de busca por soluções alternativas para as demandas dos recursos hídricos, que são responsáveis por muitas das questões, é proibitivo e, na melhor das hipóteses, apenas o status quo está sendo alcançado com relação à qualidade do habitat e, na pior das hipóteses, como ainda é comumente encontrado em todo o mundo em desenvolvimento onde os recursos financeiros são limitados, a progressiva deterioração ambiental é grande.
Uma das principais razões para os problemas na pesca é que o valor dos recursos pesqueiros é geralmente mal definido e fracamente representado, em uma perspectiva econômica e social (COWX, 2002a; 2002b). A pesca é tradicionalmente manejada com base na qualidade da experiência de pesca ou no volume de captura e raramente é gerenciada a partir de uma perspectiva econômica (COWX, 2002a), uma questão resultante da escassez de informações sobre o valor econômico da pesca (ver BAKER; PIERCE, 1997; PEIRSON et al., 2001). Um grande número de trabalhos recentes ressalta o potencial elevado da pesca artesanal de pequena escala para o desenvolvimento econômico (ao nível local e nacional), mas sistematicamente destacam como o valor verdadeiro (econômico) do setor é fracamente refletetido nas estatísticas oficiais, nas discussões sobre segurança alimentar e em relação ao modo de vida (ver por exemplo, Comissão Europeia de 2000; KACZYNSKI; LOONEY, 2000; ANON, 2001). Como consequência, o peixe e a pesca não são geralmente considerados de alta prioridade ou com valor suficientemente elevado e, portanto, sofrem em face de outras prioridades economicamente e socialmente mais elevadas, como por exemplo, agricultura, produção de energia hidroelétrica ou outros esportes aquáticos. Também é geralmente apresentado como a principal restrição para a concepção de políticas adequadas de gestão dos recursos aquáticos, tanto ao nível nacional como regional. Se a pesca deve ser promovida no futuro, há uma necessidade urgente de se fazer uma avaliação defensável social e econômica da biodiversidade aquática e da pesca (COWX, 2002a). Uma vez que esta informação esteja disponível, o valor será uma ferramenta poderosa para discutir o caso da pesca. No entanto, deve-se reconhecer que não pode ser a única ferramenta utilizada, porque o valor econômico, por exemplo, de grandes estruturas de recursos aquáticos podem superar facilmente o valor da pesca. Isso ocorre principalmente porque os métodos utilizados para valoração são frequentemente voltados unicamente para a pesca e não consideram o valor econômico a montante em termos de estética, de valor de conservação e de provisão de bens e serviços, ou o valor a jusante associado ao setor dos serviços. Reverter essa filosofia vai ser um grande desafio para os gestores da pesca e conservação, mas também não será alcançado se o verdadeiro valor econômico da preservação da pesca não for apresentado (COWX, 2002b). Como mencionado anteriormente, a avaliação precisa da pesca deverá trazer um forte impulso ao desenvolvimento das atividades de pesca no futuro imediato.

No passado, a gestão dos recursos pesqueiros foi baseada na interpretação de informações sobre os estoques populacionais de peixes e reações às mudanças 
de disponibilidade (COWX, 1996). Dentro desta abordagem, os procedimentos adequados à avaliação de estoques que fornecem uma linha de base para a gestão dos recursos pesqueiros são fundamentais. Porém, ao analisar os problemas ligados à pesca do rio fica claro que essa abordagem é insuficiente. Aumentando as pressões sobre os recursos aquáticos, mostra-se que a exploração da pesca e sua conservação não podem mais ser tratados isoladamente, e que uma abordagem integrada para a gestão dos recursos aquáticos é necessária (COWX, 1998). Da mesma forma, a biodiversidade de peixes está sendo constantemente erodida, não só pela exploração de peixes diretamente, mas principalmente através da degradação de seu habitat. Felizmente, as exigências de sustentabilidade, que cresceram a partir da Cúpula Mundial sobre Desenvolvimento Sustentável (CMDS), em 1992, colocaram ênfase na necessidade não só para gerir os recursos explorados, mas também para promover a biodiversidade. Infelizmente, o CMDS não endossou a pesca, mas isso foi corrigido na WSSD de 2002, em Johanesburgo. Assim, os conflitos entre os interesses de vários usuários devem ser resolvidos pela participação de todos os intervenientes no processo de gestão e na definição de áreas prioritárias para conservação e preservação da biodiversidade (BRUMMETT; TEUGELS, 2003; DARWALL; VIÉ, 2003). Isto pode ser conseguido através de um planejamento integrado e manejo dos recursos aquáticos. Planos de gestão de bacia hidrográfica, tanto em escala nacional e multinacional que, por exemplo, serão obrigatórios sob a nova Directiva-Quadro no Domínio da Água (DQA) da União Europeia vão apoiar este processo, mas o perfil de exploração da pesca no sentido mais amplo e a conservação da pesca precisa ser ampliada e estar mais bem integrada no processo de planejamento. Sem essa participação, o futuro do peixe do rio e da pesca permanece incerto.

Planejamento e manejo de recursos aquáticos, como sugerido acima, devem ser multidisciplinares, e terem uma abordagem interativa lidando com todos os grupos de usuários existentes e potenciais, incluindo o uso de terras das margens dos rios. Devem permitir que questões mais amplas do que aquelas relacionadas a uma única atividade, neste caso a pesca fluvial, devam ser levadas em conta durante o processo de tomada de decisão sobre uma atividade e seu provável efeito sobre o meio ambiente e outras atividades, ou inversamente, o efeito provável em outras atividades da pesca. Para que este processo seja eficaz, os dados sobre a importância social e econômica de cada recurso são necessários; sem eles, as atividades economicamente mais fortes, como o desenvolvimento de energia hidrelétrica se sobreporão.
Muitas das fontes de conflitos entre usuários dos recursos aquáticos encontram-se na dificuldade de comunicação entre grupos de usuários, a falta de um mecanismo de diálogo ou a falha de se compreender os objetivos comuns. No entanto, a falta de diálogo entre grupos de usuários frequentemente surge por falta de vontade por parte do grupo mais forte para discutir a alocação de recursos com o grupo minoritário. Uma solução poderia ser a melhor cooperação entre os atores dentro de, por exemplo, uma estrutura de cogestão (SEN; RAAKJAER; NIELSEN, 1996), desafiando as rotinas presentes. Um elemento essencial para a cogestão é a responsabilidade da partilha contínua de tomada de decisões entre o governo, pescadores e outros grupos de interesse. Comanejo é um possível mecanismo que pode garantir que o elemento humano seja levando em conta. Inclusão de todas as partes interessadas nos sistemas de cogestão garante que as decisões refletem melhor as condições local, social, econômico e ambiental. Nos países em desenvolvimento, da cogestão está sendo promovida em muitas pescas com o desenvolvimento de responsabilidade para as comunidades ribeirinhas. $\mathrm{Na}$ Europa e América do Norte, abordagens menos participativas de cogestão é mais comum de ser aplicada, com muitas pescarias em águas interiores sendo geridas conjuntamente pelos pescadores e funcionários do governo. Em ambos os casos, no entanto, o objetivo continua o mesmo, a sustentabilidade da exploração dos recursos e biodiversidade para as gerações futuras.

Da mesma forma, há uma necessidade de desenvolver parcerias com as partes interessadas nos ecossistemas afetados para fortalecer e implementar as atividades relacionadas com peixes e pesca e desenvolver mecanismos para influenciar os outros atores. Para isso, os cientistas devem expandir a sua gama de atividades de monitoração e divulgação do estado dos estoques das populações e espécies para uma posição mais influente e trabalho preventivo. Eles devem usar os melhores dados disponíveis para educar outras partes interessadas e o público em geral. Eles precisam ser envolvidos na avaliação precisa do impacto ambiental e programas de reabilitação para discutir o caso do peixe e da pesca, ou seja, há uma necessidade de desenvolver uma abordagem de risco para o manejo da pesca. Há também a necessidade de desenvolver medidas fiscais, tais como o "princípio do poluidor-pagador" e cumprimento da legislação através dos canais apropriados e instituições. Isso só será conseguido através da valoração dos recursos pesqueiros, um ponto que está agindo contra o lobby da pesca e será essencial para a integração em planos de gestão das bacias hidrográficas. Como anteriormente salientado, há uma necessidade urgente de adaptar os instrumentos de avaliação ambiental 
e econômico para valorizar a importância social e econômica da pesca em água doce e biodiversidade. Até que isto seja realizado, o peixe e a pesca continuarão com baixa prioridade em todo o processo de consulta e continuará a ser difícil atrair investimento ou crédito para a proteção da pesca.

Independentemente dos mecanismos de implementação, os gestores e usuários dos recursos precisam de um verdadeiro valor econômico de seus recursos para defender a sua posição no conflito e cenários de desenvolvimento. Isto irá aumentar a capacidade dos beneficiados da pesca de rio (águas continentais) para comunicar e influenciar em todos os níveis da sociedade. Neste contexto, é importante que as informações sobre valores sejam transmitidas para os políticos, planejadores e interessados, em linguagem simples. Por conseguinte, é importante entender como o valor é interpretado dentro das comunidades, isto é, entre ricos e pobres, pescador e não pescador. Isso só pode ser alcançado se as partes interessadas no setor da pesca compreenderem os motivos, os modos de operação e sistemas de recompensa de outras esferas da sociedade e se envolverem em intercâmbios cooperativos. O manejo mais efetivo dos recursos pesqueiros também exige que os cientistas aprendam novas habilidades de interagir em arenas complexas, desordenadas e confusas e não produzir informação científica na vã esperança de que os gestores e formuladores de políticas irão utilizá-las. Finalmente, os métodos de valorização dos recursos aquáticos e bens e serviços ambientais existem. A falta de progresso neste campo é em grande parte porque os cientistas e os gestores não têm diálogo ativo com os especialistas em economia ambiental e ecológica. Isto precisa ser promovido para incentivar o uso sustentável dos recursos aquáticos em geral e da pesca fluvial, em particular.

\section{REFERÊNCIAS}

ALAM M, K. Estimating the benefits of water quality improvement of the Buriganga river. In: INTERNATIONAL SYMPOSIUM ON THE MANAGEMENT OF LARGE, RIVERS FOR FISHERIES 2, 2003, Bangkok. Abstracts... 2003. Bangkok: FAO; Mekong River Commission, 2003.

ALMEIDA, O.; LORENZEN, K.; McGRATH, D. The Commercial Fishing Sector in the Regional Economy of the Brazilian Amazon. In: WELCOMME, R.L.; PETR, T. (Eds.). Proceedings of the Second International Symposium on the Management of Large Rivers for Fisheries, 2. Bangkok: FAO; Mekong River Commission, 2003. p. 15-24. (RAP Publication, 2004/17).
ANON, 2001. Report of the Seminar on Contribution of fisheries to poverty reduction in West Africa, 14-15 February 2001, Dakar.

ARLINGHAUS, R.; MEHNER, T.; COWX, I.G. Reconciling traditional inland fisheries management and sustainability in industrialised countries, with emphasis on Europe. Fish and Fisheries, v. 3, p. 261-316, 2002.

ARAUJO-LIMA, C.A.R.M.; MARTINS Jr, H.; ROUBACH, R.; GOMES, L.C.; MALTA, J.C.O.; LORENZEN, K.; ALMEIDA-VAL, V. Testing the effectivness of stock-enhancement in the Amazon floodplain to increase Colossoma yield. In: INTERNATIONAL SYMPOSIUM ON THE MANAGEMENT OF LARGE, RIVERS FOR FISHERIES 2, 2003, Bangkok. Abstracts... 2003. Bangkok: FAO; Mekong River Commission, 2003.

BAKER, D.L.; PIERCE, B.E. Does fisheries management reflect societal values? Contingent valuation evidence for the River Murray. Fisheries Management and Ecology, v. 4, p. 1-15, 1997.

BERKES, F.; COLDING, J.; FOLKE, C. Rediscovery of traditional ecological knowledge as adaptive management. Ecological Applications, v. 10, p. 12511262, 2000.

BÉNÉ, C.; NEILAND, A.E. Traditional management systems of Inland African fisheries. The case of Lake Chad Basin's riverine and floodplain fisheries. In: WELCOMME, R.L.; PETR, T. (Eds.). Proceedings of the Second International Symposium on the Management of Large Rivers for Fisheries, 2. Bangkok: FAO; Mekong River Commission, 2003. p. 67-78. (RAP Publication, 2004/17).

BISHOP, R.C.; BOYLE K, J.; WELSH, M.P. Towards total economic valuation of Great Lakes fishery resources. Transactions of the American Fisheries Society, v. 116, p. 339-345, 1987.

BRENNER, T.; BUIJSE, A.D.; LAUFF, M.; LUQUET, J.F.; STAUB, E. The present status of the river Rhine with special emphasis to the fisheries development. In: WELCOMME, R.L.; PETR, T. (Eds.). Proceedings of the Second International Symposium on the Management of Large Rivers for Fisheries, 2. Bangkok: FAO; Mekong River Commission, 2003. p. 121-148. (RAP Publication, 2004/17).

BROWN, J. J. Restoration of the fisheries of the Susquehanna and Delaware rivers, USA. In: INTERNATIONAL SYMPOSIUM ON THE MANAGEMENT OF LARGE, RIVERS FOR FISHERIES 2, 2003, Bangkok. Abstracts... 2003. Bangkok: FAO; Mekong River Commission, 2003. 
BRUMMETT, R.E.; TEUGELS, G.G. Rivers of the Lower Guinean rainforest: Biogeography and sustainable exploitation. In: WELCOMME, R.L.; PETR, T. (Eds.). Proceedings of the Second International Symposium on the Management of Large Rivers for Fisheries, 2. Bangkok: FAO; Mekong River Commission, 2003. p. 149-172. (RAP Publication, 2004/17).

COLLARES-PEREIRA, M.J; COWX, I.G.; COELHO, M.M. Conservation of freshwater fish: Options for the future. Oxford: Fishing News Books;Blackwell Science, 2002. 472 p.

CONNELLY, N.A.; BROWN, T.L.; KNUTH, B.A. Do anglers and fishery professionals think alike? Fisheries, 252: 21-25, 2000.

COWX, I.G. Rehabilitation of freshwater fisheries. Oxford: Fishing News Books; Blackwell Science, 1994. 484p.

COWX, I.G. 1996. Stock Assessment in inland fisheries. Oxford, UK, Fishing News Books, Blackwell Science. 513 pp.

COWX, I.G. Aquatic resource planning for resolution of fisheries management issues. In: HICKLEY, P.; TOMPKINS, H. (Eds.). Social, economic and management aspects of recreational fisheries. Oxford: Fishing News Books; Blackwell Science, 1998. p. 97-105.

COWX, I.G. Management and ecology of river fisheries. Oxford: Fishing News Books; Blackwell Science, 2000. 444 p.

COWX, I.G. Analysis of threats to freshwater fish conservation: Past and present challenges. In: COLLARES-PEREIRA, M.J.; COWX, I.G.; COELHO, M.M. (Eds.). Conservation of freshwater fish: Options for the future. Oxford: Fishing News Books; Blackwell Science, 2002a. p. 201-220.

COWX, I.G. Management and ecology of lake and reservoir fisheries. Oxford: Fishing News Books; Blackwell Science, 2002b. 396 p.

COWX, I.G. Recreational fishing. In: HART, P.J.B.; REYNOLDS, J.S. (Eds.). Handbook of fish biology and fisheries. v. 2. Oxford: Fishing News Books; Blackwell Science, 2002.

COWX, I.G.; WELCOMME, R.L. Rehabilitation of rivers for fish. Oxford: Fishing News Books; Blackwell Science, 2002c. 260 p.
DARWALL, W.R.T.; VIÉ J.C. Identifying important sites for conservation of freshwater biodiversity: Extending the species-based approach. In: INTERNATIONAL SYMPOSIUM ON THE MANAGEMENT OF LARGE, RIVERS FOR FISHERIES 2, 2003, Bangkok. Abstracts... 2003. Bangkok: FAO; Mekong River Commission, 2003.

DYNESIUS, M.; NILSSON, C. Fragmentation and flow regulation of river systems in the northern third of the world. Science, v. 266, p. 753-761, 1994.

EDWARDS, S.F. A critique of three economics arguments commonly used to influence fishery allocations. North American Journal of Fisheries Management, v. 11, p. 121-130, 1991.

EUROPEAN COMMISSION. Communication from the commission to the council and the European parliament. Fisheries and poverty reduction. COM2000 724 Final. Brussels: Commission of the European Communities, 2000. 20 p.

FAO. Inland fisheries: FAO technical guidelines for responsible fisheries 6 , 1997. $36 \mathrm{p}$.

FAO. Review of the state of world fisheries resources: Inland fisheries. Fisheries Circular, n. 942, 1-53p, 1999.

FAO. FISHSTAT Plus. Universal software for fishery statistical time series. Version 2.3. Data set: Capture Production 1970-2000. Rome, Fisheries Department, Fishery Information, Data and Statistics Unit, FAO, 2002.

FREYHOF, J. Freshwater fish diversity in Germany, threats and species extinction. In: COLLARES-PEREIRA, M.J.; COWX, I.G.; COELHO, M.M. (Eds.). Conservation of freshwater fish: Options for the future. Oxford: Fishing News Books; Blackwell Science, 2002a. p. 3-23.

GARCIA, S.M.; COCHRANE, K.; VAN SANTEN, G.; CHRISTY F. Towards sustainable fisheries: A strategy for FAO and the World Bank. Ocean and Coastal Management, v. 42, p. 369-398, 1999.

GREGORY, R. Nonmonetary measures of nonmarket fishery resource benefits. Transactions of the American Fisheries Society, v. 116, p. 374-380, 1987.

HAND, R.T. Protein, fat and carbohydrate food security maintenance in the Mekong Basin: Racing for rice while fumbling with fish. In: INTERNATIONAL SYMPOSIUM ON THE MANAGEMENT OF LARGE, RIVERS FOR FISHERIES 2, 2003, Bangkok. Abstracts... 2003. Bangkok: FAO; Mekong River Commission, 2003. 
HALLS, A.S.; SHANKAR, B.; BARR, J. Fish out of water: Modelling some tradeoffs between fisheries and agriculture in the floodplains of Bangladesh. In: INTERNATIONAL SYMPOSIUM ON THE MANAGEMENT OF LARGE, RIVERS FOR FISHERIES 2, 2003, Bangkok. Abstracts... 2003. Bangkok: FAO; Mekong River Commission, 2003.

HANSEN, L.T.; HALLAM, A. National estimates of the recreational value of streamflow. Water Resources Research, v. 27, p. 167-175, 1991.

HART, P.J.B.; PITCHER, T.J. Conflict, consent and cooperation: An evolutionary perspective on individual human behaviour in fisheries management. In: PITCHER, T. J.; HART, P.J.B.; PAULY, D. (Eds.). Reinventing Fisheries Management. London: Chapman \& Hall, 1998. p. 215-225.

JOHANNES, R.E.; FREEMAN, M.M.R.; HAMILTON, R.J. Ignore fishers' knowledge and miss the boat. Fish and Fisheries, v. 1, p. 257-271, 2000.

KACZYNSKI, V.M.; LOONEY, S.W. Coastal resources as an engine of economic growth and reduction of poverty in West Africa: Policy considerations. Coastal Management, v. 28, p. 235-248, 2000.

KAUNDA, E.; CHAPOTOKA, O. The conflict between poverty and river system management: The case of Malawi, Southern Africa. In: INTERNATIONAL SYMPOSIUM ON THE MANAGEMENT OF LARGE, RIVERS FOR FISHERIES 2, 2003, Bangkok. Abstracts... 2003. Bangkok: FAO; Mekong River Commission, 2003.

KEARNEY, R.E. Evaluating recreational fishing: Managing perceptions and/ or reality. In: PITCHER, T.J. (Ed.). Evaluating the benefits of recreational fisheries. Vancouver: The Fisheries Centre, 1999. p. 9-14.

KEARNEY, R.E. Recreational fishing: Value is in the eye of the beholder. In: PITCHER, T.J.; HOLLINGWORTH, C.E. (Eds.). Recreational fisheries: Ecological, economic and social evaluation. Oxford: Blackwell Science, 2002. p. $17-33$.

KOTCHIN, M.J.; REILING, S.D. Environmental attitudes, motivations and contingent valuation of non-use values: a case study involving endangered species. Ecological Economics, v. 32, p. 93-107, 2000.

LACKEY, R.T. Options and limitations in fisheries management. Environmental Management, v. 3, p. 109-112, 1979.
LYONS, J.; HICKLEY, P.; GLEDHILL, S. An evaluation of recreational fishing in England and Wales. In: PITCHER, T.J.; HOLLINGWORTH, C.E. (Eds.). Recreational fisheries: Ecological, economic and social evaluation. Oxford: Blackwell Science, 2002. p. 144-155.

MACKINSON, S.; NOTTESTAD, L. Combining local and scientific knowledge. Reviews in Fish Biology and Fisheries, v. 8, p. 481-490, 1998.

NAVRUD, S. Economic valuation of the external costs of fuel cycles. Testing the benefit transfer approach. In: ALMEIDA, A.T. (Ed.). Models for integrated electricity resource planning. Dordrecht: Kluwer Academic Publishers, 1994. p. 49-66.

McGRATH, D.G.; CASTRO, F.; FUTEMMA, C.; AMARAL, B.D.; CALABRIA, J. Fisheries and evolution of resource management on the Lower Amazon floodplain. Human Ecology, v. 21, p. 167-195, 1993.

McGRATH, D.; SILVA, U.; CROSSA, M. A traditional floodplain fishery of the lower Amazon River, Brazil. NAGA, p. 4-11. Jan-Mar. 1998.

NAVRUD, S. Economic valuation of inland recreational fisheries: Empirical studies and their policy use in Norway. Fisheries Management and Ecology, v. 8, p. 369-382, 2001.

NGUYEN KHOA, S.; SMITH, L.; LORENZEN, K.; GARAWAY, C. 2003. Assessment and management of irrigation impacts on tropical inland fisheries: A case study from Sri Lanka. In: INTERNATIONAL SYMPOSIUM ON THE MANAGEMENT OF LARGE, RIVERS FOR FISHERIES 2, 2003, Bangkok. Abstracts... 2003. Bangkok: FAO; Mekong River Commission, 2003.

NGUYEN KHOA, S.; LORENZEN, K.; GARAWAY, C. Impacts of irrigation development on capture fisheries in the rice-based farming systems of southern Laos. In: INTERNATIONAL SYMPOSIUM ON THE MANAGEMENT OF LARGE, RIVERS FOR FISHERIES 2, 2003, Bangkok. Abstracts... 2003. Bangkok: FAO; Mekong River Commission, 2003.

OLSSON, P.; FOLKE, C. Local ecological knowledge and institutional dynamics for ecosystem management: A study of Lake Racken watershed, Schweden. Ecosystems, v. 4, p. 85-104, p. 2001.

PEIRSON, G.; TINGLEY, D.; SPURGEON, J.; RADFORD, A. Economic evaluation of inland fisheries in England and Wales. Fisheries Management and Ecology, v. 8, p. 415-424, 2001. 
PETR, T. (Ed.). Inland fishery enhancements. FAO Fisheries Technical Paper, v. 374. P. 1-463, 1998.

PITCHER, T.J.; HOLLINGWORTH, C.E. Recreational fisheries: Ecological, economic and social evaluation. Oxford: Blackwell Science, 2002. 271p. (Fish and Aquatic Resources Series, 8.)

POLLOCK, K.H.; JONES, C.M.; BROWN, T.L. Angler surveys methods and their applications in fisheries management. Bethesda; Maryland: American Fisheries Society, 1994. $371 \mathrm{p}$

PUSEY, B.J. The translocation of recreationally satisfying fishes is detrimental to the maintenance of local biodiversity: Sleepy cod and other translocated species in the Burdekin River. In: INTERNATIONAL SYMPOSIUM ON THE MANAGEMENT OF LARGE, RIVERS FOR FISHERIES 2, 2003, Bangkok. Abstracts... 2003. Bangkok: FAO; Mekong River Commission, 2003.

RADONSKI, G. Issues and attitudes impacting fisheries now and into the twentyfirst century. Fisheries, v. 205, p. 10-12, 1995.

RANDALL, A. Total economic value as a basis for policy. Transactions of the American Fisheries Society, v. 116, p. 325-335, 1987.

RIECHERS, R.K.; FEDLER, A.J. An overview of economic impact and value of recreational fisheries. In: Miranda, L.E.; VRIES, D.R. de. (Eds.). Multidimensional approaches to reservoir fisheries management. Bethesda; Maryland: American Fisheries Society, 1996. p. 245-250.

SCHORR, M.S.; SAH, J.; SCHREINER, D.F.; MEADOR, M.R.; HILL, L.G. Regional economic impact of the Lake Texoma Oklahoma-Texas striped bass fishery. Fisheries, v. 205, p. 14-18, 1995.

SEN, S.; RAAKJAER, N. J. Fisheries co-management: A comparative analysis. Marine Policy, v. 20, p. 405-418, 1996

SMITH, C.L. The life cycle of fisheries. Fisheries, v. 114, p. 20-25, 1986.

TALHELM, D.R.; LIBBY, L.W. In search of a total value assessment framework: SAFR symposium overview and synthesis. Transactions of the American Fisheries Society, v. 116, p. 293-301, 1987.
VAN BRAKEL, M.L.; MUIR, J.F.; ROSS, L.G. Modelling for aquaculture related development, poverty and needs in the Mekong Basin. In: INTERNATIONAL SYMPOSIUM ON THE MANAGEMENT OF LARGE, RIVERS FOR FISHERIES 2, 2003, Bangkok. Abstracts... 2003. Bangkok: FAO; Mekong River Commission, 2003.

VANDERPOOL, C.K. Social impact assessment and fisheries. Transactions of the American Fisheries Society, v. 116, p. 479-485, 1987.

VITOUSEK, P.M.; MOONEY, H.A.; LUBCHENCO, J.; MELILLO, J.M. Human domination of earth's ecosystems. Science, v. 277, p. 494-499, 1997.

WEITHMAN, A.S. Socioeconomic benefits of fisheries. In: KOHLER, C.C.; HUBERT, W.A. (Eds.). Inland Fisheries Management in North America. 2. ed. Bethesda, Maryland: American Fisheries Society, 1999. p. 193-213.

WELCOMME, R.L. Principles and approaches to river fisheries management. In: COWX, I.G. (Ed.). Management and ecology of river fisheries. Oxford: Fishing News Books; Blackwell Science, 2000. p. 331-345.

WELCOMME, R.L. Inland fisheries: Ecology and management. Oxford: Fishing News Books; Blackwell Science, 2001. 358 p.

WELCOMME, R.; NAEVE, H. (Eds.). An international symposium on fisheries and society Budapest, Hungary, 01-03 June, 2000. Fisheries Management and Ecology, v. 84-85, p. 283-462, 2001.

WILLIS, K.G.; GARROD, G.D. Angling and recreation values of low-flow alleviation in rivers. Journal of Environmental Management, v. 57, p. 71-83, 1999. 
